\title{
Fabrication of Hollow Core-Shell Type Si/C Nanocomposites by a Simple Process
}

\author{
Kei Wakabayashi, Daichi Yamaura, Kazuki Ito, Naoya Kameda, and Toshio Ogino \\ Graduate school of Engineering, Yokohama National University, \\ Tokiwadai 79-5, Hodogaya-ku, Yokohama 240-8501, Japan
}

(Received 14 February 2017; Accepted 28 April 2017; Published 27 May 2017)

\begin{abstract}
We have successfully fabricated hollow core-shell type Si/C nanocomposites using a simple process. Si powder was grinded to form Si nanoparticles, mixed with sucrose as a carbon source and ammonium chloride as an expansion agent, and finally annealed in Ar atmosphere. During the annealing, carbon hollow spheres encapsulating $\mathrm{Si}$ nanoparticles were spontaneously fabricated through dehydrogenation reaction of the sucrose to form carbon balloons and the balloon expansion by ammonium gas generated during ammonium chloride decomposition. Volume of the empty spaces in the core-shell structure can be controlled by the rising rate in the annealing temperature. This method is suitable for industrial production of hollow $\mathrm{Si} / \mathrm{C}$ nanocomposites because of its simplicity.
\end{abstract} [DOI: $10.1380 /$ ejssnt.2017.69]

Keywords: Nanostructure chemistry, processing and fabrication; Nano-particles, quantum dots, and supra-molecules; Silicon; Carbon

\section{INTRODUCTION}

Silicon ( $\mathrm{Si}$ ) is one of the most promising anode materials in the next generation of lithium ion batteries (LIBs) because of its extremely high capacity, which is expected to reach ten times higher than that of graphite used in the current LIBs [1-3]. Before application of Si anodes to LIBs, however, some serious drawbacks should be solved. In charge/discharge cycles, 300-400\% volume change occurs in the Si anodes [4, 5]. When using bulk Si for anode materials, volume expansion is concentrated around the Si surface regions because Li ions are accumulated near the surface owing to their low diffusivity in $\mathrm{Si}$, resulting in destruction of the Si crystal structure. The low diffusivity of $\mathrm{Li}$ ions also deteriorates charging rate and capacity because the deep regions of Si bulk are not effectively utilized for Li ion storage.

To overcome the above-mentioned drawbacks, replacement of the bulk Si with silicon nanoparticles (Si-NPs), silicon nanowires (Si-NWs), silicon thin films, and silicon with hollow nanospaces [6-13]. In these nanostructured Si materials, the large volume change and the low Li ion diffusivity are relaxed because the whole Si anodes are easily filled with Li ions [14]. Although nanoparticles are the most easily fabricated nanostructures, their electrical conductivity is not enough for high rate charge-discharge cycles because electrical connection between nanoparticles are much poorer than the bulk Si. To improve the electrical conduction in $\mathrm{Si}-\mathrm{NPs}, \mathrm{Si} /$ carbon $(\mathrm{Si} / \mathrm{C}$ ) nanocomposites are promising, such as Si-graphite, Si-carbon nanotubes, Si-graphene, and Si-reduced graphene oxide [1519].

Among many $\mathrm{Si} / \mathrm{C}$ nanocomposites that have already been reported, hollow core-shell type Si/C nanocomposites with empty spaces are suitable for LIBs [20-25]. Hollow core-shell structures are widely used in electrochemical supercapacitor [26], drug delivery [27] and photocatalyst [28], where the cores and the shells have different functions. Regarding the hollow core-shell type Si/C nanocomposites, aggregation of Si-NPs can be prevented by the C-shells, and conductive path between the Si-NPs and the current collector can be formed by the contact through C-shells. The empty space is the most important part in this structure because mechanical stress caused by lithium ion intercalation/deintercalation can be relaxed without deformation of the C-shells using the space in the core-shell structure as a buffer space. Although hollow core-shell type Si/C nanocomposites potentially have excellent properties, their fabrication processes that have been reported are complicated and expensive. A general fabrication technique for hollow core-shell type structures is based on removal of surface layers of core-materials by calcination or dissolution [29]. For example, Li proposed a fabrication process that consists of formation of $\mathrm{SiO}_{2}$ sacrifice layers on the $\mathrm{Si}$ powder, carbon coating on the $\mathrm{SiO}_{2}$ layers, and removal of the $\mathrm{SiO}_{2}$ layers to form hollows [30]. In this process, the $\mathrm{SiO}_{2}$ layers were grown by thermal oxidation of the Si-NPs or deposited using tetraethylorthosilicate (TEOS), and the carbon shells were formed by precursor deposition using wet process. Then, the precursor was carbonized by furnace annealing, and the $\mathrm{SiO}_{2}$ layers were etched out by immersing the $\mathrm{Si}_{-} \mathrm{SiO}_{2}-\mathrm{C}$ composites in a hydrogen fluoride (HF) solution. Use of HF solution is also one of the drawbacks in this process. In this paper, we report on a much simpler fabrication method to fabricate hollow core-shell type $\mathrm{Si}-\mathrm{C}$ nanocomposites, where we used combination of mechanochemical reaction, which is one of the methods to produce composite particles [31], and sugar-blowing technique, which is one of the synthesis methods to fabricate three-dimensional graphene [32].

\section{EXPERIMENTAL METHOD}

Figure 1 shows fabrication process that we propose. As-purchased Si powder of about $150 \mu \mathrm{m}$ in average diameter was mixed with sucrose $\left(\mathrm{C}_{12} \mathrm{H}_{22} \mathrm{O}_{11}\right)$ and ammonium chloride $\left(\mathrm{NH}_{4} \mathrm{Cl}\right)$, and grinded using a mortar. These materials were provided by Nacalai tesque. The obtained carbon-precursor-coated Si-NPs were dispersed in ethanol after the mixing process and deposited on a graphite/copper foil as a substrate. The samples were annealed for $3 \mathrm{~h}$ in Ar atmosphere. The annealing temperature and its rising rate were varied between $400^{\circ} \mathrm{C}$ and $1000^{\circ} \mathrm{C}$ and between $10^{\circ} \mathrm{C} / \mathrm{min}$ and $66^{\circ} \mathrm{C} / \mathrm{min}$, respectively. Weight ratio of the $\mathrm{C}_{12} \mathrm{H}_{22} \mathrm{O}_{11}$ and $\mathrm{NH}_{4} \mathrm{Cl}$ was fixed to be $1: 1$, and the ratio of $\mathrm{Si}-\mathrm{NPs}$ and the $\mathrm{C}_{12} \mathrm{H}_{22} \mathrm{O}_{11} / \mathrm{NH}_{4} \mathrm{Cl}$-mixture was varied from 1:1 to $1: 5$. 


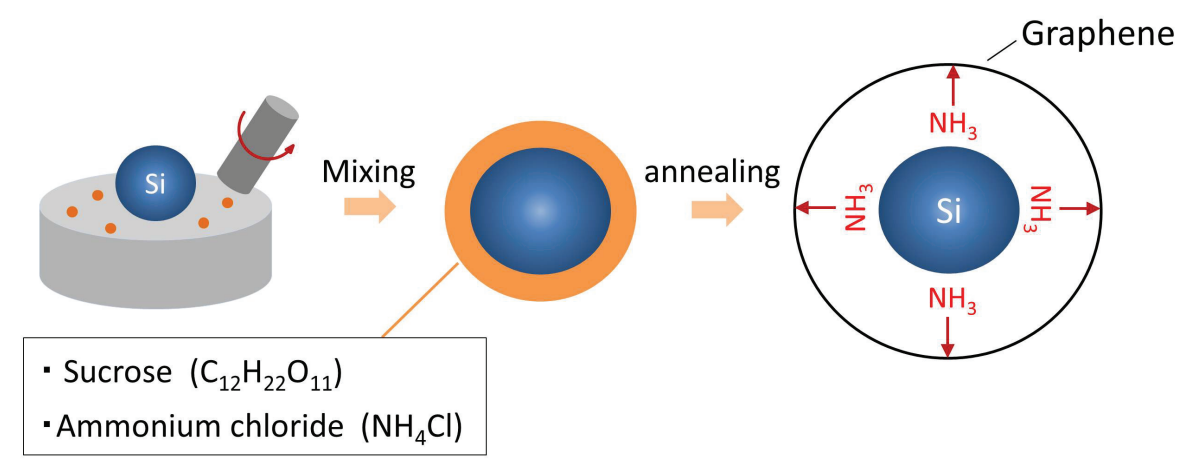

FIG. 1. Fabrication process of hollow core-shell type Si/C nanocomposites.
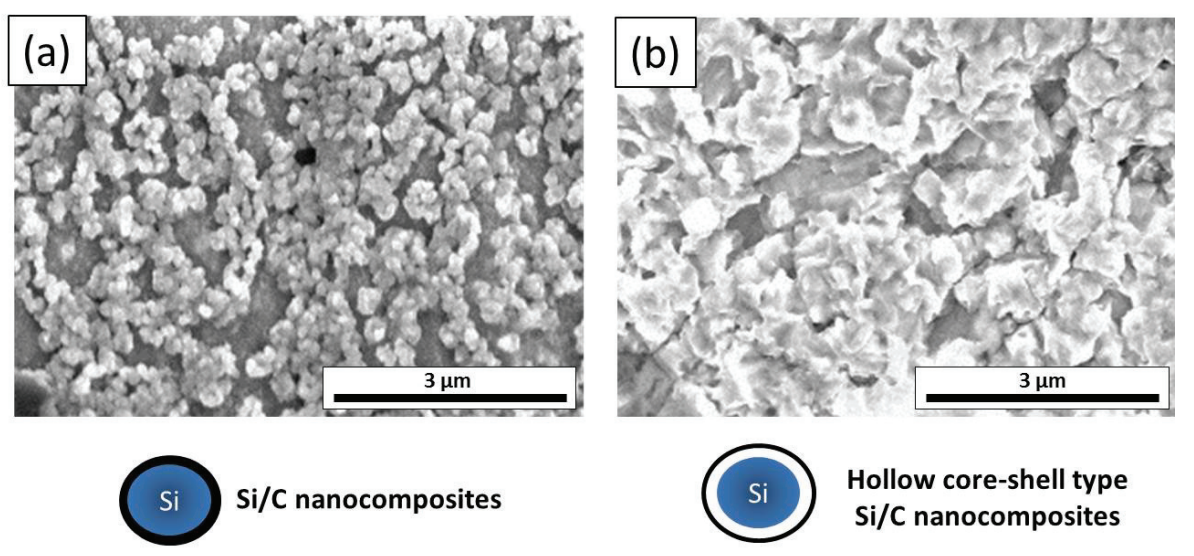

FIG. 2. SEM images of (a) Si/C nanocomposites synthesized by the process shown in Fig. 1 without addition of $\mathrm{NH}_{4} \mathrm{Cl}$ to the sucrose and (b) $\mathrm{Si} / \mathrm{C}$ nanocomposites with addition of $\mathrm{NH}_{4} \mathrm{Cl}$ to the sucrose.

Morphology of the fabricated $\mathrm{Si} / \mathrm{C}$ nanocomposites was observed by scanning electron microscope (SEM) and graphitic material formation was examined by Raman spectroscopy.

\section{A. Results and Discussion}

Figure 2 shows the Si/C nanocomposites prepared from whole processes shown in Fig. 1: (a) without addition of $\mathrm{NH}_{4} \mathrm{Cl}$ in the sucrose mixing step and (b) with addition of $\mathrm{NH}_{4} \mathrm{Cl}$ in a weight ratio of sucrose : $\mathrm{NH}_{4} \mathrm{Cl}=1: 1$. In Fig. 2(a), size of the $\mathrm{Si} / \mathrm{C}$ core-shell particles is only slightly larger than that of the original Si-NPs, $150 \mu \mathrm{m}$ in average diameter, whereas it is much larger than the original size when $\mathrm{NH}_{4} \mathrm{Cl}$ was added, as shown in Fig. 2(b). Because $\mathrm{NH}_{4} \mathrm{Cl}$ is decomposed into gaseous ammonia and hydrogen chloride above $335^{\circ} \mathrm{C}$, the added $\mathrm{NH}_{4} \mathrm{Cl}$ almost completely disappears from the synthesized solid products after annealing above $400^{\circ} \mathrm{C}$ and does not contribute to the volume change. Therefore, the observed volume increase caused by the $\mathrm{NH}_{4} \mathrm{Cl}$ addition should be apparent expansion of the carbon shells synthesized by the sucrose carbonization, which indicates that hollow spaces are formed by the gaseous products during the annealing process.

Figure 3 shows SEM images of the hollow core-shell type $\mathrm{Si} / \mathrm{C}$ nanocomposites when weight ratio of $\mathrm{Si}-\mathrm{NPs}$ and the $\mathrm{C}_{12} \mathrm{H}_{22} \mathrm{O}_{11} / \mathrm{NH}_{4} \mathrm{Cl}$-mixture was varied from 1:1 to $1: 5$. The nanocomposite size becomes larger as the ratio of the $\mathrm{C}_{12} \mathrm{H}_{22} \mathrm{O}_{11} / \mathrm{NH}_{4} \mathrm{Cl}$-mixture was increased. This suggests that the space size between the Si-NP cores and the C-shells can be controlled by the weight ratio of carbon source materials.

Figure 4 shows SEM images of the hollow core-shell $\mathrm{Si} / \mathrm{C}$ nanocomposites synthesized using the rising rate in the annealing temperature of (a) $66^{\circ} \mathrm{C} / \mathrm{min}$, (b) $33^{\circ} \mathrm{C} / \mathrm{min}$, and (c) $10^{\circ} \mathrm{C} / \mathrm{min}$. In these images, Si-NPs encapsulated with the C-shells were clearly observed by the "see-through" mode of SEM [33]. White grains with clear edges correspond to Si-NP cores, and hollow spaces between the Si-NPs and the C-shell are observed. The spherical, smooth shape of the C-shells observed in Fig. 4(b) also suggests hollow structure formation because simple carbonization process without expansion by a vapor pressure would form C-shells with random shape. Carbonshell size increases as the rising rate in the annealing temperature decreases owing to longer inflating time. In Fig. 4, the C-shells formed at the rising rate of $66^{\circ} \mathrm{C} / \mathrm{min}$ and $10^{\circ} \mathrm{C} / \mathrm{min}$ exhibit rough surfaces, whereas those at $33^{\circ} \mathrm{C} / \mathrm{min}$ smooth ones. This may suggest that there is an optimal rising rate in the annealing temperature for each weight ratio of source materials. Within our experiments, the optimal condition is $33^{\circ} \mathrm{C} / \mathrm{min}$ for $1: 1$ in weight 

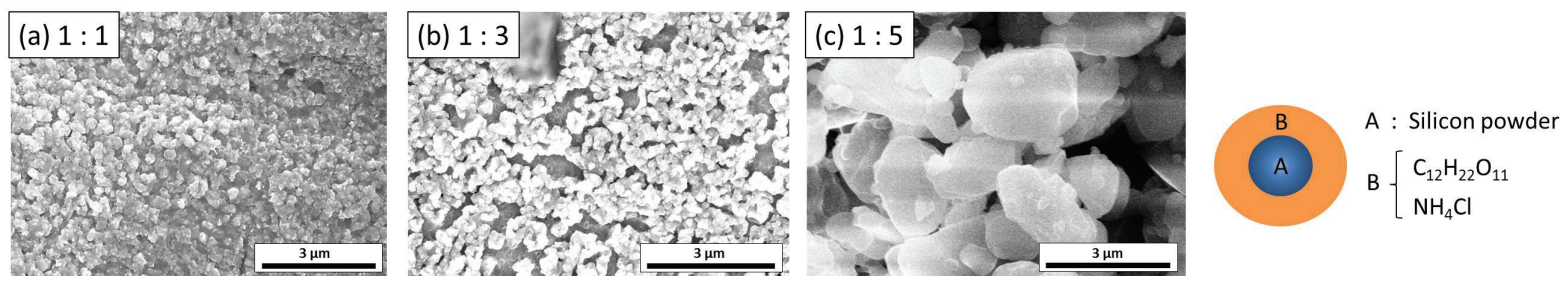

FIG. 3. SEM images of Si/C nanocomposites synthesized with weight ratio of Si-NPs : $\mathrm{C}_{12} \mathrm{H}_{22} \mathrm{O}_{11} / \mathrm{NH}_{4} \mathrm{Cl}-\mathrm{mixture}=(\mathrm{a}) 1: 1$, (b) $1: 3$, (c) $1: 5$.

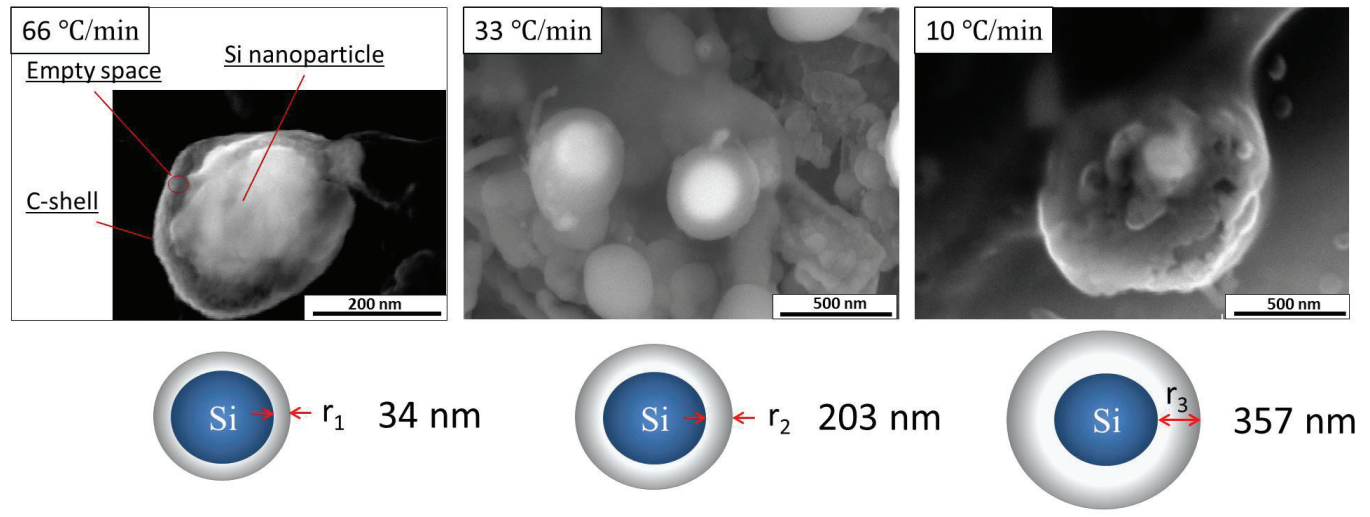

- Rising rate in annealing temperature

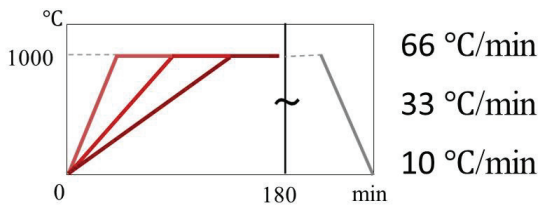

FIG. 4. See-through SEM images of the Si/C nanocomposites when the rising rate in the annealing temperature was varied to be (a) $66^{\circ} \mathrm{C} / \mathrm{min}$, (b) $33^{\circ} \mathrm{C} / \mathrm{min}$, and (c) $10^{\circ} \mathrm{C} / \mathrm{min}$.

ratio of $\mathrm{Si}-\mathrm{NPs}$ : $\mathrm{C}_{12} \mathrm{H}_{22} \mathrm{O}_{11} / \mathrm{NH}_{4}$ Cl-mixture. However, shape of the encapsulated $\mathrm{Si}$ cores should be considered as another cause for the surface roughness of the C-shells.

Figure 5 shows Raman spectra of hollow core-shell type $\mathrm{Si} / \mathrm{C}$ nanocomposite fabricated under 1:1 in weight ratio of Si-NPs : $\mathrm{C}_{12} \mathrm{H}_{22} \mathrm{O}_{11} / \mathrm{NH}_{4} \mathrm{Cl}$-mixture and $33^{\circ} \mathrm{C} / \mathrm{min}$ in the rising rate in the annealing temperature. Raman peaks from crystalline $\mathrm{Si}$, non-defective (G-peak) and defective (D-peak) $\mathrm{sp}^{2}$-bonded carbon lattice are observed at $520 \mathrm{~cm}^{-1}, 1600 \mathrm{~cm}^{-1}$, and $1350 \mathrm{~cm}^{-1}$, respectively. Broadening of graphitic peaks was also observed in graphene prepared from sucrose in the previous report [34]. The D and $G$ peak intensities increased as increase in the annealing temperature or as decrease in the rising rate in the annealing temperature, as shown in Figure 5 (b) and (c). From the Raman spectra, we cannot obtain thickness of the synthesized graphitic products. In the previous report, graphene fabricated from sucrose is more defective and apparently thicker than that from fructose [34]. From the Raman spectra in Fig. 5 and the previously reported results, it is suggested that the carbon shells in the present process are not high-quality fewlayered graphene, but thick graphitic materials.

Finally, we discuss design of the core-shell type Si/C nanocomposites from the point of LIB anodes. Optimal volume of the empty space is determined by considering $\mathrm{Si}$ volume change in charge-discharge cycles in LIBs. If the empty space is too large, contact areas between Si-cores and carbon-shells are too small, resulting in poor conductive path [35]. If the empty space is too small, destruction of carbon-shells would occur by the stress from the expanded Si cores [23]. The optimal volume ratio between a Si-core without $\mathrm{Li}$ ions $\left(\mathrm{V}_{1}\right)$ and a $\mathrm{C}$-shell $\left(\mathrm{V}_{2}\right)$ should be about 4.0, which is the maximum volume change in the lithium ion intercalation/deintercalation cycles. The volume ratio $\mathrm{V}_{2} / \mathrm{V}_{1}$ can be expressed as

$$
\frac{V_{2}}{V_{1}}=\frac{4 / 3 \pi r_{2}^{3}}{4 / 3 \pi r_{1}^{3}}
$$

where $r_{1}$ and $r_{2}$ are the radius of a Si-core and that of a C-shell, as shown in Fig. 6. From the SEM image in Fig. 6, we obtain $\mathrm{V}_{2} / \mathrm{V}_{1}=4.5$, which is almost the same as the optimal value. When the weight ratio of SiNPs : $\mathrm{C}_{12} \mathrm{H}_{22} \mathrm{O}_{11} / \mathrm{NH}_{4}$ Cl-mixture is $1: 3$ or $1: 5$, it was found that empty space would be too large to use as hollow $\mathrm{Si} / \mathrm{C}$ nanocomposites for LIBs. From these results, the optimal weight ratio of Si-NPs : $\mathrm{C}_{12} \mathrm{H}_{22} \mathrm{O}_{11} / \mathrm{NH}_{4} \mathrm{Cl}$ mixture and the rising rate in the annealing temperature are around $1: 1$ and $33^{\circ} \mathrm{C} / \mathrm{min}$, respectively within our experiments. Because controllability of empty spaces also 
(a)

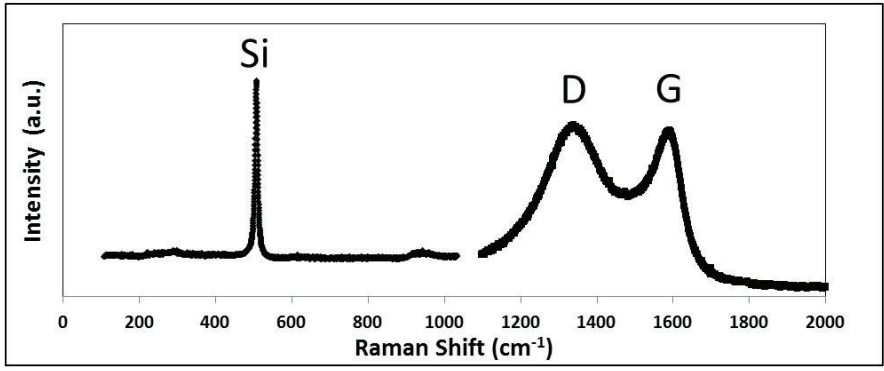

(b)

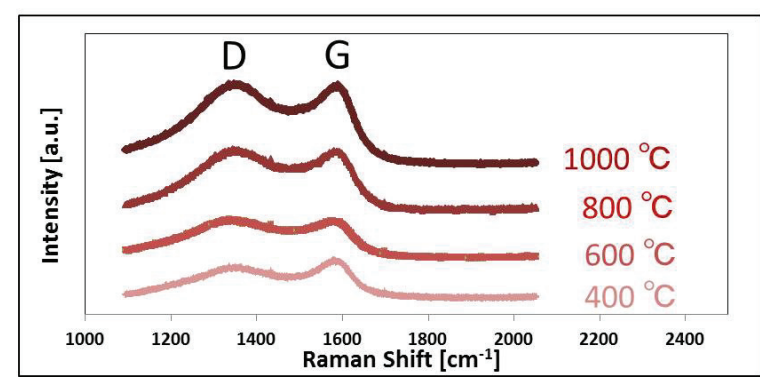

(c)

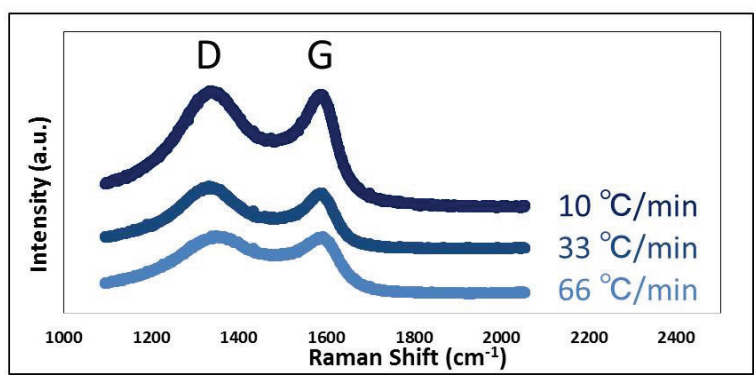

FIG. 5. Raman spectra of (a) hollow core-shell type Si/C nanocomposites fabricated for 1:1 in weight ratio of Si-NPs : $\mathrm{C}_{12} \mathrm{H}_{22} \mathrm{O}_{11} / \mathrm{NH}_{4} \mathrm{Cl}$-mixture at the rising rate of $33^{\circ} \mathrm{C} / \mathrm{min}$ in the annealing temperature, (b) their annealing temperature dependence, and (c) their temperature rising rate dependence.
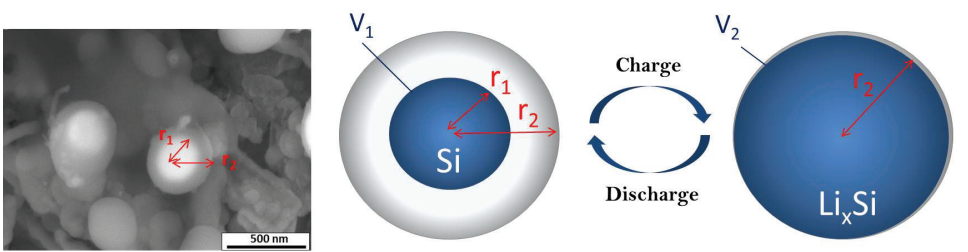

This study

$\frac{V_{2}}{V_{1}}=\frac{4 / 3 \pi r_{2}^{3}}{4 / 3 \pi r_{1}^{3}} \quad \frac{V_{2}}{V_{1}}=4.5 \frac{r_{2}}{r_{1}}=1.65$

FIG. 6. Design of hollow core-shell type Si/C nanocomposites for LIB anodes.

depends on uniformity in the Si-NP size, use of bead mills or mechanofusion process $[36,37]$ would be preferable for mass-production of core-shell type $\mathrm{Si} / \mathrm{C}$ nanocomposites. In the present study, we fabricated hollow core-shell type nanocomposites containing Si cores, but this method can be applied to many other core-materials with specific functionality.

\section{CONCLUSIONS}

In this study, hollow core-shell type $\mathrm{Si} / \mathrm{C}$ nanocomposites have been successfully fabricated by a simple, safe process consisting of the mixing of source materials and the annealing. The size of the empty spaces in the hol- low core-shell structure can be controlled by the rising rate in the annealing temperature. The present method is promising for novel anode materials of LIBs because encapsulated Si-NPs can repeat expansion and shrinkage keeping their positions inside the C-shells. Because production amount of the nanocomposites may be increased by using dry mechanical particle compositing method, this technique will be suitable for industrial applications.

\section{ACKNOWLEDGMENTS}

This work was partly supported by a Grant-in-Aid for Scientific Research (15K13361) from the Ministry of Education, Culture, Sports, Science and Technology, and by CREST-JST.
[1] T. Takamura, M. Uehara, J. Suzuki, K. Sekine, and K. Tamura, J. Power Sources 158, 1401 (2006).
[2] T. D. Bogart, A. M. Chockla, and B. A. Korgel, Curr. Opin. Chem. Eng. 2, 286 (2013). 
[3] U. Kasavajjula, C. Wang, and A. J. Appleby, J. Power Sources 163, 1003 (2007).

[4] R. Teki, M. K. Datta, R. Krishnan, T. C. Parker, T.-M. Lu, P. N. Kumta, and N. Koratkar, Small 5, 2236 (2009).

[5] J. R. Szczech and S. Jin, Energy Environ. Sci. 4, 56 (2011).

[6] H. Kim, M. Seo, M. H. Park, and J. Cho, Angew. Chemie - Int. Ed. 49, 2146 (2010).

[7] K. Peng, J. Jie, W. Zhang, and S.-T. Lee, Appl. Phys. Lett. 93, 33105 (2008).

[8] H. Guo, H. Zhao, C. Yin, and W. Qiu, Mater. Sci. Eng. B 131, 173 (2006).

[9] Y. Yao, M. T. McDowell, I. Ryu, H. Wu, N. Liu, L. Hu, W. D. Nix, and Y. Cui, Nano Lett. 11, 2949 (2011).

[10] M. Ge, J. Rong, X. Fang, and C. Zhou, Nano Lett. 12, 2318 (2012).

[11] J. Liang, X. Li, Y. Zhu, C. Guo, and Y. Qian, Nano Res. 8, 1497 (2014).

[12] Y. Nishijima, R. Komatsu, S. Ota, G. Seniutinas, A. Balčytis, and S. Juodkazis, APL Photonics 1, 076104 (2016).

[13] E. P. Ivanova, J. Hasan, H. K. Webb, G. Gervinskas, S. Juodkazis, V. K. Truong, A. H. F. Wu, R. N. Lamb, V. A. Baulin, G. S. Watson, J. A. Watson, D. E. Mainwaring, and R. J. Crawford, Nat. Commun. 4, 2838 (2013).

[14] X. H. Liu, L. Zhong, S. Huang, S. X. Mao, T. Zhu, and J. Y. Huang, ACS Nano 6, 1522 (2012).

[15] Z. S. Wen, J. Yang, B. F. Wang, K. Wang, and Y. Liu, Electrochem. Commun. 5, 165 (2003).

[16] J. Shu, H. Li, R. Yang, Y. Shi, and X. Huang, Electrochem. Commun. 8, 51 (2006).

[17] L.-F. Cui, L. Hu, J. Wook, and Y. Cui, ACS Nano 4, 3671 (2010).

[18] J. K. Lee, K. B. Smith, C. M. Hayner, and H. H. Kung, Chem. Commun. 46, 2025 (2010).

[19] J. Chang, X. Huang, G. Zhou, S. Cui, P. B. Hallac, J. Jiang, P. T. Hurley, and J. Chen, Adv. Mater. 26, 758 (2014).

[20] W. Li, Q. Wang, K. Cao, J. Tang, H. Wang, L. Zhou, and H. Yao, Compos. Commun. 1, 1 (2016).
[21] X. Xiao, W. Zhou, Y. Kim, I. Ryu, M. Gu, C. Wang, G. Liu, Z. Liu, and H. Gao, Adv. Funct. Mater. 25, 1426 (2015).

[22] X.-Y. Zhou, J.-J. Tang, J. Yang, J. Xie, and L.-L. Ma, Electrochim. Acta 87, 663 (2013).

[23] N. Liu, Z. Lu, J. Zhao, M. T. McDowell, H.-W. Lee, W. Zhao, and Y. Cui, Nat. Nanotechnol. 9, 187 (2014).

[24] N. Liu, H. Wu, M. T. McDowell, Y. Yao, C. Wang, and Y. Cui, Nano Lett. 12, 3315 (2012).

[25] X. Feng, H. Cui, R. Miao, N. Yan, T. Ding, and Z. Xiao, Ceram. Int. 42, 589 (2015).

[26] D. Han, P. Xu, X. Jing, J. Wang, D. Song, J. Liu, and M. Zhang, J. Solid State Chem. 203, 60 (2013).

[27] S.-W. Cao and Y.-J. Zhu, J. Phys. Chem. C 112, 12149 (2008).

[28] D. Wang, T. Hisatomi, T. Takata, C. Pan, and M. Katayama, Angew. Chem. Int. Ed. 52, 11252 (2013).

[29] M. B. Gawande, A. Goswami, T. Asefa, H. Guo, A. V. Biradar, D.-L. Peng, R. Zboril, and R. S. Varma, Chem. Soc. Rev. 44, 7540 (2015).

[30] X. Li, P. Meduri, X. Chen, W. Qi, M. H. Engelhard, W. Xu, F. Ding, J. Xiao, W. Wang, C. Wang, J.-G. Zhang, and J. Liu, J. Mater. Chem. 22, 11014 (2012).

[31] K. Tanno, KONA Powder and Particle Journal 8, 74 (1990).

[32] X. Wang, Y. Zhang, C. Zhi, X. Wang, D. Tang, Y. Xu, Q. Weng, X. Jiang, M. Mitome, D. Golberg, and Y. Bando, Nat. Commun. 4, 2905 (2013).

[33] M. Nagase, A. Fujiwara, K. Kurihara, and H. Namatsu, Jpn. J. Appl. Phys. 42, 318 (2003).

[34] Q. Huang, D. Zeng, S. Tian, and C. Xie, Mater. Lett. 83, 76 (2012).

[35] S. Chen, M. L. Gordin, R. Yi, G. Howlett, H. Sohn, and D. Wang, Phys. Chem. Chem. Phys. 14, 12741 (2012).

[36] T. Yokoyama, K. Urayama, M. Naito, M. Kato, and T. Yokoyama, KONA Powder and Particle Journal 5, 59 (1987).

[37] M. Nechiche, V. Gauthier-Brunet, D. Eyidi, S. Azem, and S. Dubois, J. Am. Ceram. Soc. 98, 4058 (2015). 